\title{
A CASE STUDY ON THE USAGE OF RESIDENTIAL RESIDUAL WASTE FOR ENERGY GENERATION VIA BIODIGESTER-PYROLYZER AND STEAM RANKINE CYCLE
}

\author{
Ferdinand Manegdeg ${ }^{1}$, Paolo Yves De Silos ${ }^{2}$, and Jonathan Medrano ${ }^{1}$ \\ ${ }^{1}$ Department of Mechanical Engineering, College of Engineering, University of the Philippines Diliman, Quezon \\ City, Philippines, Tel: +63289818500 local 3130, email: upme@coe.upd.edu.ph \\ ${ }^{2}$ Energy Engineering Program, College of Engineering, University of the Philippines Diliman, \\ Quezon City, Philippines, Tel: +639772047298, email: pldesilos1@up.edu.ph
}

Received Date: January 10, 2020; Revised Date: May 11, 2020; Acceptance Date: September 10, 2020

\begin{abstract}
The design study concerns the creation of a waste-to-energy conversion plant in the City of Muntinlupa to lessen the amount of non-recyclable municipal solid wastes that ends up in the landfill. Using the developed criteria, the cluster that can be used are the biodegradable and residual waste portions of the municipal solid wastes. In consideration of the processes for power generation, Rankine cycle was seen as the best alternative powerplant type to use the biogas and synthetic gas produced from the biodigester and pyrolyzer, respectively. The powerplant project has a capacity of $8.6 \mathrm{MW}$, a return of investment of $12 \%$, an internal rate of return of $19 \%$, and a payback period of 5 years.
\end{abstract}

Keywords: Biodigester, Pyrolyzer, Rankine cycle, Residual waste, Waste-to-energy

\section{Introduction}

The continuous growth and development in urbanization and industrialization, together with increasing population growth, results to an exponential increment in the quantity of municipal solid waste (MSW). The MSW includes metal, paper, organic waste, cardboard, leather, wood, rubber, plastics, and the like. In the southern part of Asia, about 70 million tons of wastes is generated per year. The value is expected to triple by the year 2025 [1]. Hence, there is a need to mitigate and control municipal solid wastes through proper management systems. However, countries having relatively lower Gross Domestic Product (GDP), such as Sri Lanka, Malaysia, Thailand, and the Philippines, are having trouble in coping up with this problem due to lack of resources and facilities in taking care of the solid wastes [2].

The Philippines' waste generation rate (WGR) for rural and urban sectors are 0.3 $\mathrm{kg} / \mathrm{capita} /$ day and $0.5 \mathrm{~kg} / \mathrm{capita} /$ day, respectively. This translates to $35,580,000 \mathrm{~kg}$ of wastes generated every day. Of this value, $74 \%$ is attributed to residential areas. In addition, Metro Manila has a waste generation rate of $0.7 \mathrm{~kg} / \mathrm{capita} /$ day or a generation of about $8,636,000 \mathrm{~kg}$ of wastes per day [3]. 
Estimations show that a government unit spends at most $\$ 100 /$ capita/year in a state wherein insufficient action is taken on proper municipal solid waste management. This is observably higher than the estimated $\$ 7 /$ capita/year that a government spends when proper waste management mechanisms are applied [4].

The objectives of the study are to (a) determine an appropriate Local Government Unit (LGU) in the Philippines for plant setting, (b) identify the waste cluster for fuel source, (c) evaluate the suitable energy conversion technology in utilizing the waste, (d) determine the appropriate powerplant to be used for electricity generation, and (e) calculate the financial feasibility of the plant.

\section{Methodology}

\section{Sampling Design}

Stratified random sampling was applied on the process of selection of location, fuel type, energy conversion technologies, and powerplant type. For simplicity, Simple Multi-Attribute Rating Technique (SMART) was used in all of the sampling and selection processes. It is a decisionmaking tool used for accounting qualitative and quantitative factors which may affect the system. Moreover, the decision-making process is composed of the alternatives and parameters with various values and weights. The values are obtained from literature or primary and secondary sources. The weighted average of the values are calculated to allow the normalization of the relative importance into weights totaling to 1 . A provisional decision and sensitivity analysis is done after. A screening criteria was applied as well to narrow the alternatives as data sensitivity treatment. Equations (1) to (4) were applied to values obtained from the literature and primary data. Findings were plotted on Figures 2 to 4 .

$$
\begin{gathered}
u\left(a_{i}\right)=\sum_{j=1}^{m} w_{j} u_{i}\left(a_{i}\right), i=1,2, \ldots, m \\
n=\frac{w_{j}}{\sum w_{j}} \\
u_{i}\left(a_{i}\right)=\frac{c_{\text {out }}-c_{\min }}{c_{\max }-c_{\min }} \\
c_{\text {out }} i=u_{i}\left(a_{i}\right), 1=0 ; 2=0.5 ; 3=1
\end{gathered}
$$

where:

$\mathrm{n}$ is the normalized value of criteria

$\mathrm{W}_{\mathrm{j}}$ is the weight value of criteria

$\Sigma \mathrm{W}_{\mathrm{j}}$ is the total weight of all the criteria

uiai is the utility value of the criteria

$\mathrm{c}_{\max }$ is the maximum value criteria

$\mathrm{c}_{\min }$ is the minimum value criteria

couti is the value criterion to -I 
In the selection of location to be used among the 17 cities and municipality in Metro Manila for the study, several quantifying concept were used: GDP per capita, economic growth rate, population, proximity to Laguna Bay for water source, number of households, land area, and crime index. The screening criteria applied was that GDP per capita should not be less than 10,000 and LGU location should be near the Laguna Bay for water source. Afterwards, the cities of Makati, Muntinlupa, and Taguig were left wherein Muntinlupa got the highest value at normalized weight.

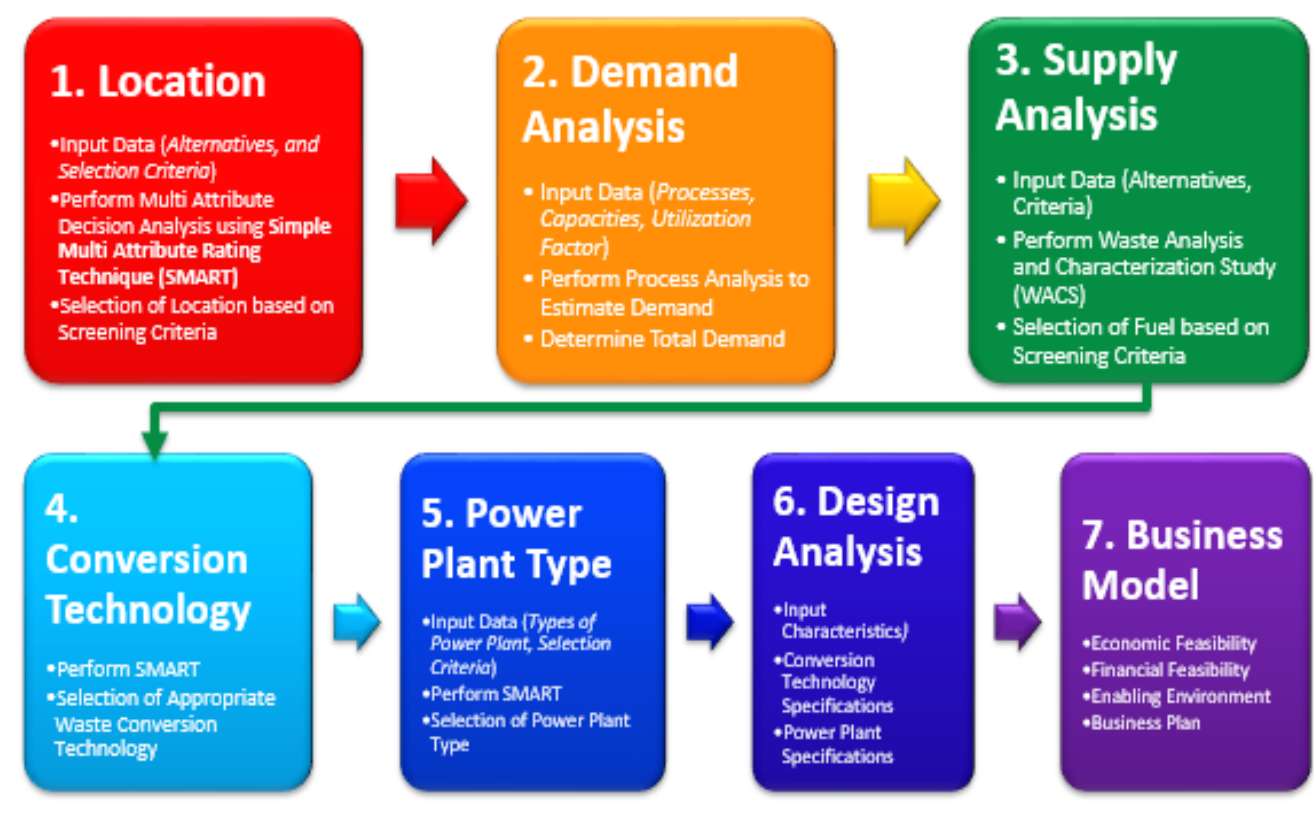

Figure 1. Methodology flow

The City of Muntinlupa is a highly urbanized city in the southernmost portion of Metro Manila. As of 2018, it has a population of 531,932. It is bordered by Las Piñas in the west, Parañaque in the northwest, Taguig in the North, Bacoor and Dasmariñas in Southwest, and San Pedro and the Laguna de Bay in the east. The city is known for its medical tourism, the New Bilibid Prison, expensive residential communities, and large malls. It has a GDP per capita of $\mathrm{PhP}$ 11,500 (USD 225.36) [5].

Table 1 shows the waste composition percentage and the corresponding computed heating value, as received from ESC. Moreover, the MSW has a bulk moisture content of 39.5\% as shown in Table 2.

Table 1. Summary of Muntinlupa MSW Composition

\begin{tabular}{lll} 
Parameter & Composition in MSW, \% & Higher Heating Value, MJ/kg \\
\hline Biodegradable & 43.39 & 4.36 \\
Recyclable & 29.17 & - \\
Special Waste & 0.15 & - \\
Residual Waste for Diversion & 5.00 & 19.85 \\
Residuals & 22.29 & \\
\hline
\end{tabular}




$$
C V_{\text {feed }}=\sum C V_{i} * x_{i}
$$

where:

$\mathrm{CV}_{\text {feed }}$ is the total heating value of the feed at constant volume $(\mathrm{MJ} / \mathrm{kg})$

$\mathrm{CV}_{\mathrm{i}}$ is the heating value of the component $(\mathrm{MJ} / \mathrm{kg})$

$\mathrm{x}_{\mathrm{i}}=$ percent composition of the waste type from the total residual waste $(\%)$

Applying Equation (5),

$\mathrm{CV}_{\text {feed }}=(4.36 \mathrm{MJ} / \mathrm{kg})(0.4339)+(19.85 \mathrm{MJ} / \mathrm{kg})(0.05+0.2229)$

$\mathrm{CV}_{\text {feed }}=1.89 \mathrm{MJ} / \mathrm{kg}+5.42 \mathrm{MJ} / \mathrm{kg}$

$\mathrm{CV}_{\text {feed }}=7.30 \mathrm{MJ} / \mathrm{kg}$

The calorific value of the feed must be at least $7 \mathrm{MJ} / \mathrm{kg}$, and never fall to less than $6 \mathrm{MJ} / \mathrm{kg}$, for practical energy output.

Table 2. Moisture Content of MSW in Muntinlupa City According to Generating Sector

\begin{tabular}{ll} 
Sector & Moisture Content, \% \\
\hline Low-income Residential & 24.5 \\
Mid-income Residential & 47.6 \\
High-income Residential & 13.3 \\
Commercial & 56.6 \\
Markets & 80.6 \\
Industrial & 27.3 \\
Institutional & 16 \\
All Sectors & 39.5 \\
\hline
\end{tabular}

\section{Selection Processes}

The SMART scheme was also used for the selection of the appropriate energy conversion technologies and powerplant type, the results of which are shown in Figures 2, 3, and 4. Based from Table 1, there are two types of wastes that can be used for electricity generation: biodegradable wastes $(43.39 \%)$ and residual wastes $(27.29 \%)$. Selection criteria include cost, operating temperature, energy potential, reliability, technological maturity, waste separation and reduction system, and environmental impacts. For the selection of energy conversion technology for the biodegradable wastes, the alternatives were the biodigester, incinerator, and gasifier. On the other hand, for the selection of energy conversion technology for the residual wastes, the alternatives were pyrolyzer, autoclave, microwave, and plasma. For Figures 2-4, the y-axis corresponds to the selection criteria, while the x-axis corresponds to the normalized weight of the alternatives. 


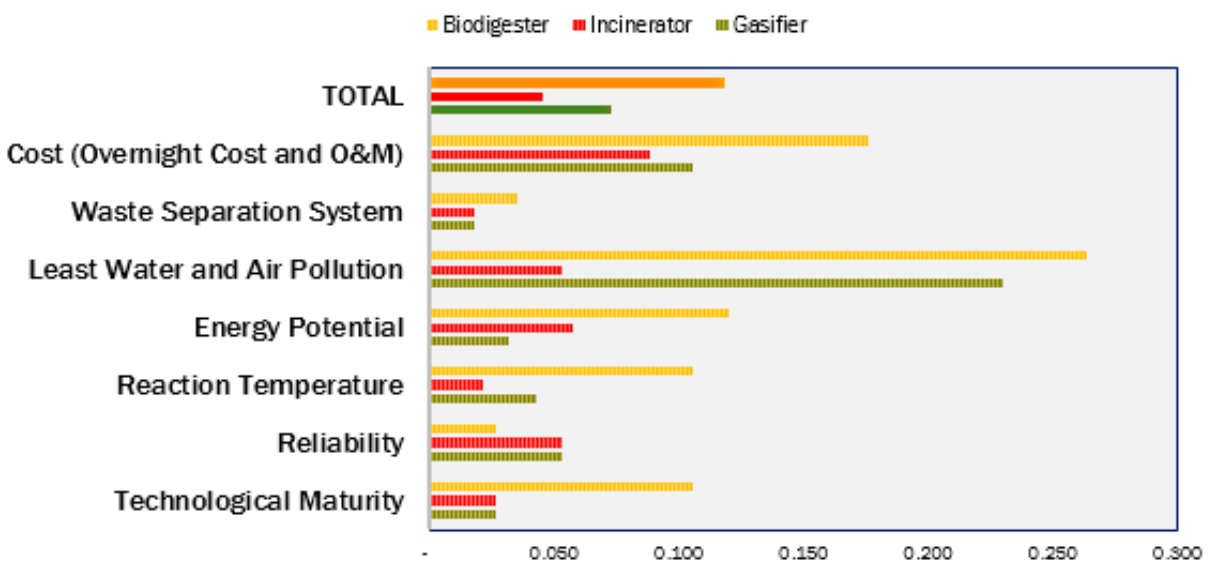

Figure 2. Selection of energy conversion technology for biodegradable wastes

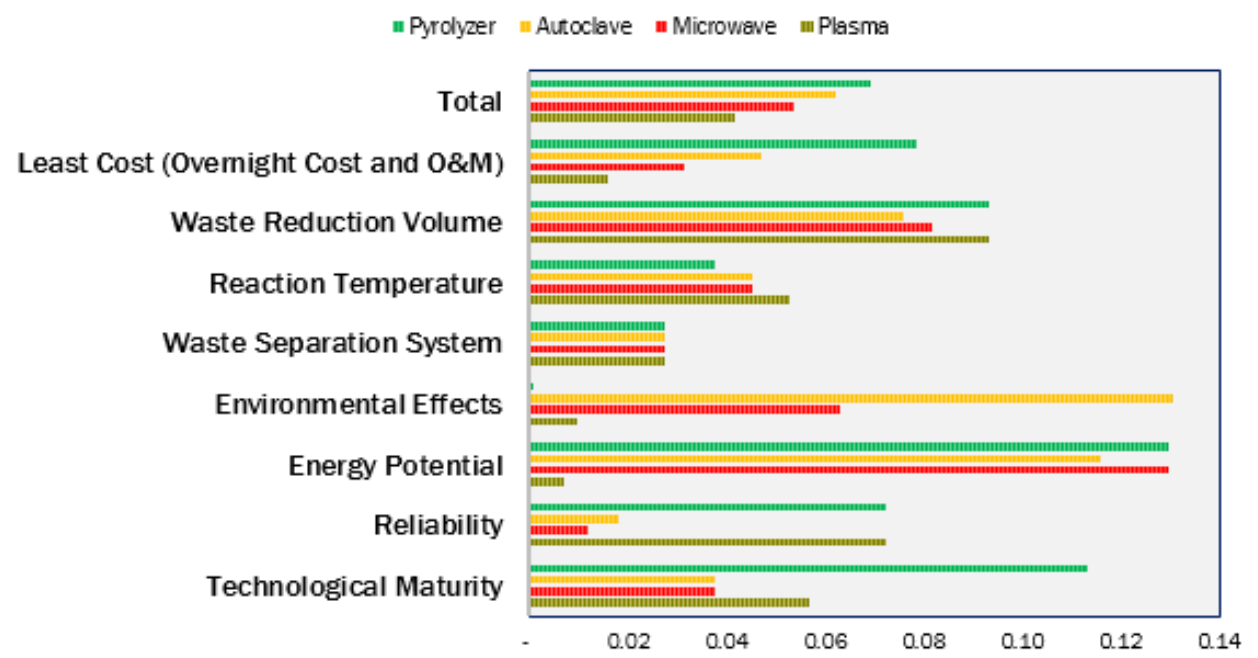

Figure 3. Selection of energy conversion technology for residual wastes

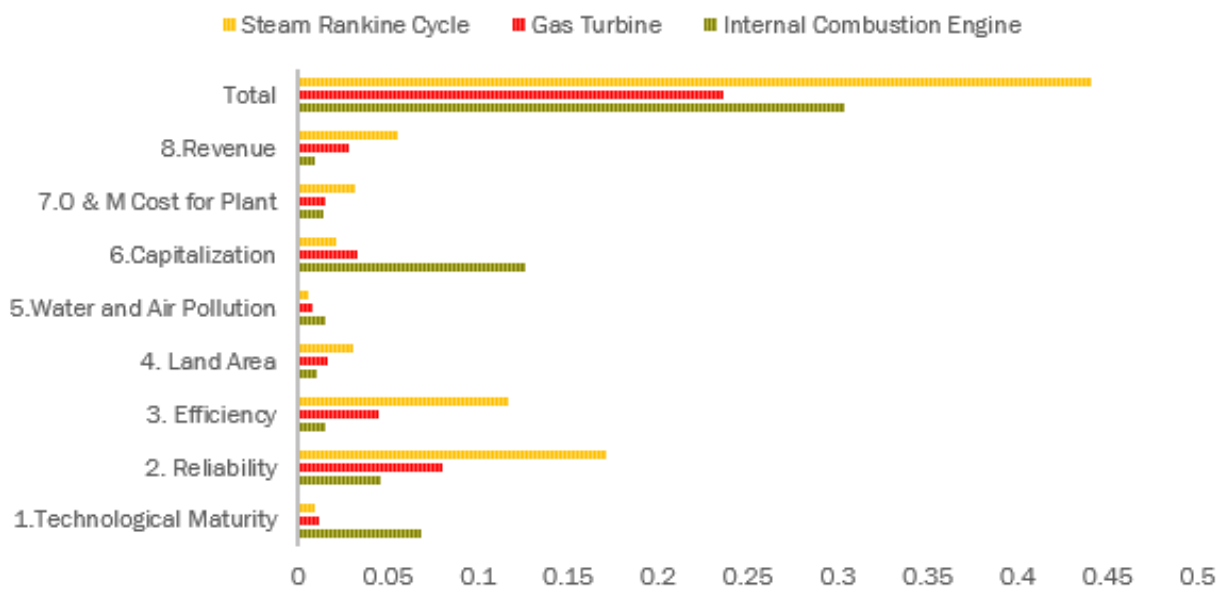

Figure 4. Selection of powerplant type 
In addition, the type of powerplant to be used was selected among steam Rankine cycle, gas turbine, and internal combustion engine. The selection criteria involved were cost, reliability, estimated revenue, efficiency, technological maturity, environmental impacts, and land area needed.

\section{Results and Discussion}

After applying the selection criteria for the energy conversion technologies, biogester and pyrolyzer were selected for the biodegradable and residual wastes, respectively. Incinerators could have been an efficient waste conversion technology with a volume reduction capacity of $70-90 \%$, compared to a biodigester with a capacity of $45-50 \%$, but the Philippines Clean Air Act of 1999 enforces a ban on incineration, which is defined as the burning of municipal, biomedical and hazardous waste, which process emits poisonous and toxic fumes [8].

For the powerplant type, the steam Rankine cycle was selected. The energy demand (in $\mathrm{kW}$ ) was determined with respect to the current population and population after 10 years of Muntinlupa City. The information on the proposed powerplant supply or fuel, which is the waste generated, was provided by the Environmental Sanitation Center of Muntinlupa City.

\section{Demand and Supply}

In 2018, Muntinlupa City had a population of 531,932 and energy demand of 45 MW. For 2028, the city is estimated to have a population of 635,600 .

Table 3. Demand analysis of Muntinlupa City

\begin{tabular}{lll} 
& \multicolumn{1}{l}{ Year } & \\
\cline { 2 - 3 } Parameter & $\mathbf{2 0 1 8}$ & $\mathbf{2 0 2 8}$ \\
\hline Population & 531,932 & 635,600 \\
Energy Demand, MW & 45 & 54 \\
\hline
\end{tabular}

$$
\begin{aligned}
& \text { Energy Demand, } k W h=(\text { Population })\left(746 \frac{k W h}{\text { capita }}\right) \\
& \text { Energy Demand, } k W=(\text { Energy, } k W h) / 8766
\end{aligned}
$$

From Equations (6) and (7), the city has an estimated energy demand of $54 \mathrm{MW}$ by 2028 based on population growth and economic activity shown in Table 3. Prior to 2018, waste generation was estimated to be 70,000 to 74,000 tons of waste consisting of biodegradables and residuals which comprises almost $95 \%$ of the total waste composition. Waste generation has a correlation with the population and economic activity of the city.

\section{Waste-to-Energy Conversion}

Figure 5 shows the schematic diagram for the waste disposal and waste to energy conversion. Residential waste is first sorted into biodegradable, residual, and recyclable waste in a material 
recovery facility. Recyclable waste is set aside and placed in recycling facilities. Biodegradable waste is pre-processed before it is fed to the biodigester. Residual waste is also pre-processed before going to the pyrolyzer.

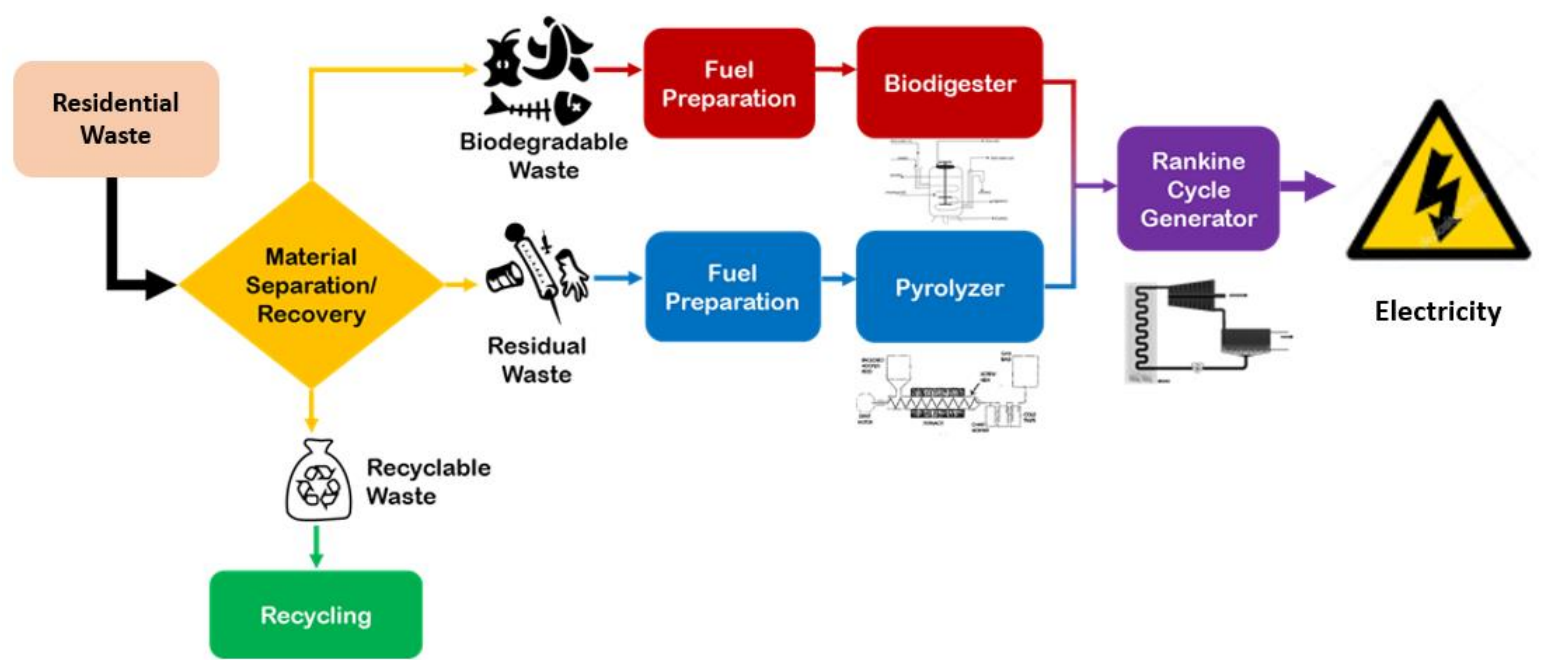

Figure 5. Residential waste-to-energy conversion schematic diagram

In Figure 6, biogas produced by the biodigester and syngas produced by the pyrolyzer are used as fuel for the Steam Rankine Cycle Generator. The generator produces energy, which can help supply the electricity needs of the city.

$$
\text { Plant Capacity, } M W=\frac{\left(\text { supply, } \frac{\mathrm{kg}}{\mathrm{yr}}\right)\left(\eta_{\text {Gen }}\right)\left(\eta_{\text {Turbine }}\right)\left(\eta_{\text {Boiler }}\right)\left(\eta_{\text {Waste Conv }}\right)(\mathrm{CV})}{(3600)(24)(365)}
$$

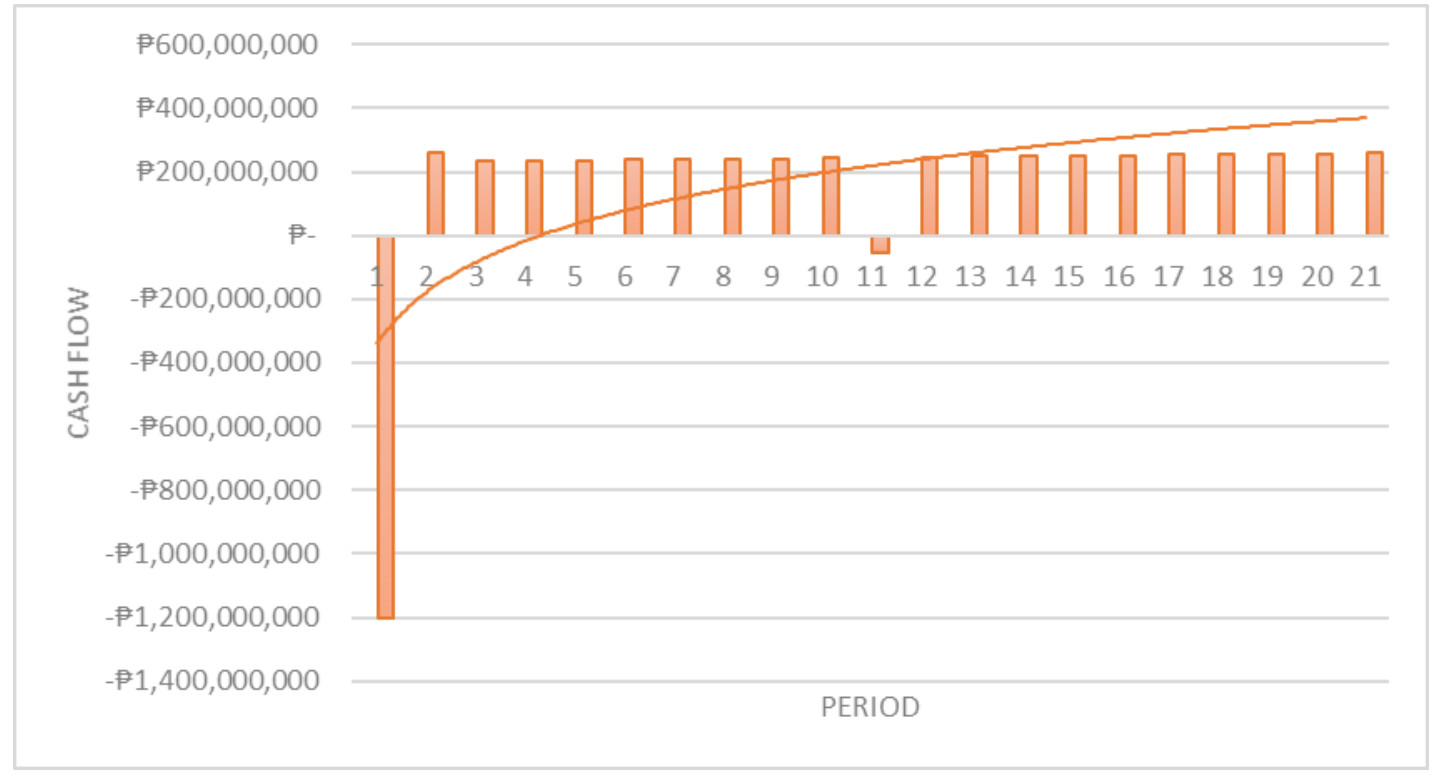

Figure 6. Cashflow of the powerplant 
Equation (8) and the values shown in Table 4 were used to calculate the plant capacity, where $\eta_{\text {Gen }}, \eta_{\text {Turbine, }} \eta_{\text {Boiler, }} \eta_{\text {waste conv }}$ are the estimated efficiencies of the Rankine cycle generator, turbine, boiler, and waste conversion, respectively [2], [3], [7]. The calculated plant capacity was 8.6 MW annually.

Table 4. Values used for plant capacity estimation

\begin{tabular}{lc}
\multicolumn{1}{c}{ Parameter } & Value \\
\hline Fuel Supply (WtE), kg/yr & $116,918,261$ \\
Mass Percent of Biodegradables, \% & 43.39 \\
Mass of Biodegradables, kg/yr & $50,730,833$ \\
CV of Biodegradables, kJ/kg & 4,360 \\
Mass Percent of Residuals, \% & 27.29 \\
CV of Residuals, $\mathrm{kJ} / \mathrm{kg}$ & 19,850 \\
Combined Fuel Supply, kg/yr & $82,637,827$ \\
Combined Fuel Supply, kg/s & 2.62 \\
Pyrolyzer Efficiency, \% & 75 \\
Biodigester Efficiency, \% & 80 \\
Combined Waste Conversion Efficiency, \% & 60 \\
Combined Mass Fuel Supply, kg/s & 1.57 \\
Calorific Value of WtE Feed, kJ/kg & $7,308.90$ \\
Boiler Efficiency, \% $\%$ & 90 \\
Turbine Efficiency, \% & 85 \\
Generator Efficiency, \% & 98 \\
\hline
\end{tabular}

\section{Financial Feasibility}

The capital cost for the power plant is given by Equation (9):

$$
\text { Capital Cost }=\text { Direct Cost }+ \text { Indirect Cost }+ \text { Material Cost }
$$

Direct costs includes the equipment costs, delivery charges, freight insurances, building and facilities, installation cost, land cost and administrative cost. Indirect costs includes engineering, supervision, design and construction, construction field expense and operational cost, contractor's fee and the building permit and licenses. The total CAPEX is estimated to be PhP 1,200,000 (USD 23,700) and O\&M is 25\% of CAPEX for every 10 years. Profit can be obtained through the sale of electricity (PhP 320,274,000 or USD 6,325,200), tipping fee ( $\mathrm{PhP}$ $90,820,000$ or USD 1,794,000), materials recovery (PhP 43,550,000 or USD 860,000), and possibly on potential carbon credit. Moreover, the freight, insurance, taxes, and overhead expenses are estimated to be $\mathrm{PhP} 195,951,000$ (USD 3,870,000). The key variables that were considered to assess the economic viability of the project include the capital cost, the operation and maintenance cost (O\&M), and the fuel cost.

Discounted Cash Flow is the value of the cash flow in the current period and the discount factor.

$$
D C F=\frac{C F_{1}}{(1+r)_{1}}+\frac{C F_{2}}{(1+r)_{2}}+\frac{C F_{n}}{(1+r)_{n}}
$$


where:

$\mathrm{CF}$ is the cash flow for the given year $\left(\mathrm{CF}_{1}\right.$ for year $1, \mathrm{CF}_{2}$ for year $2, \mathrm{CF}_{\mathrm{n}}$ for additional years). $\mathrm{r}$ is the discount rate.

The main indicator of the profitability of the investment object is the net present value (NPV). It is the difference between the total amount of discounted incomes and the volume of the investment and it is an analytical assessment of the economic potential of the project. On the other hand, the internal rate of return (IRR) shows the maximum requirement for an annual return on the invested money. If the internal rate of return is higher than the expected return on investment (ROI), then the investment is expected to be effective (i.e. IRR > ROI). Moreover, the return on investment is calculated as the ratio of total profit, taking into account the discount factor, to the initial investment. The profit-to-investment ratio, or the discounted profitability index (PI), is the ratio of net present value (NPV) to initial investment. If the indicator is greater than 1 , the investment of capital can be considered as effective [8].

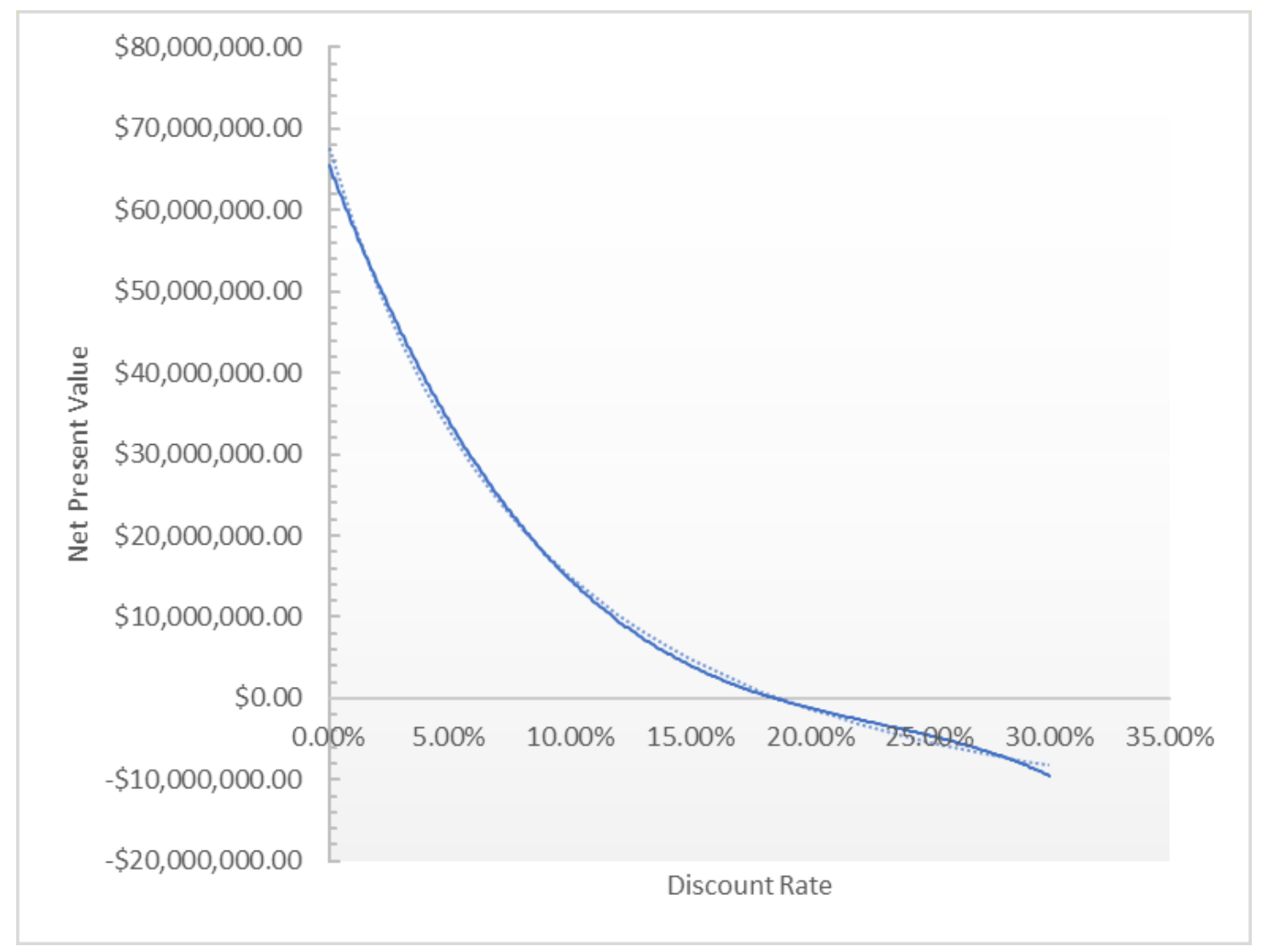

Figure 7. Simulated cashflow of the powerplant at $10 \%$ DCF

From the cashflow in Figure 6, it can be seen that the break-even is at 4.5 years and the payback is at 5 years. In addition, from the simulated cash flow in Figure 7, a Discounted Cash Flow at a $10 \%$ discount rate results to a discounted profitability index (PI) of 1.63. Since it is higher than unity, effectiveness of the investment capital is implied. 


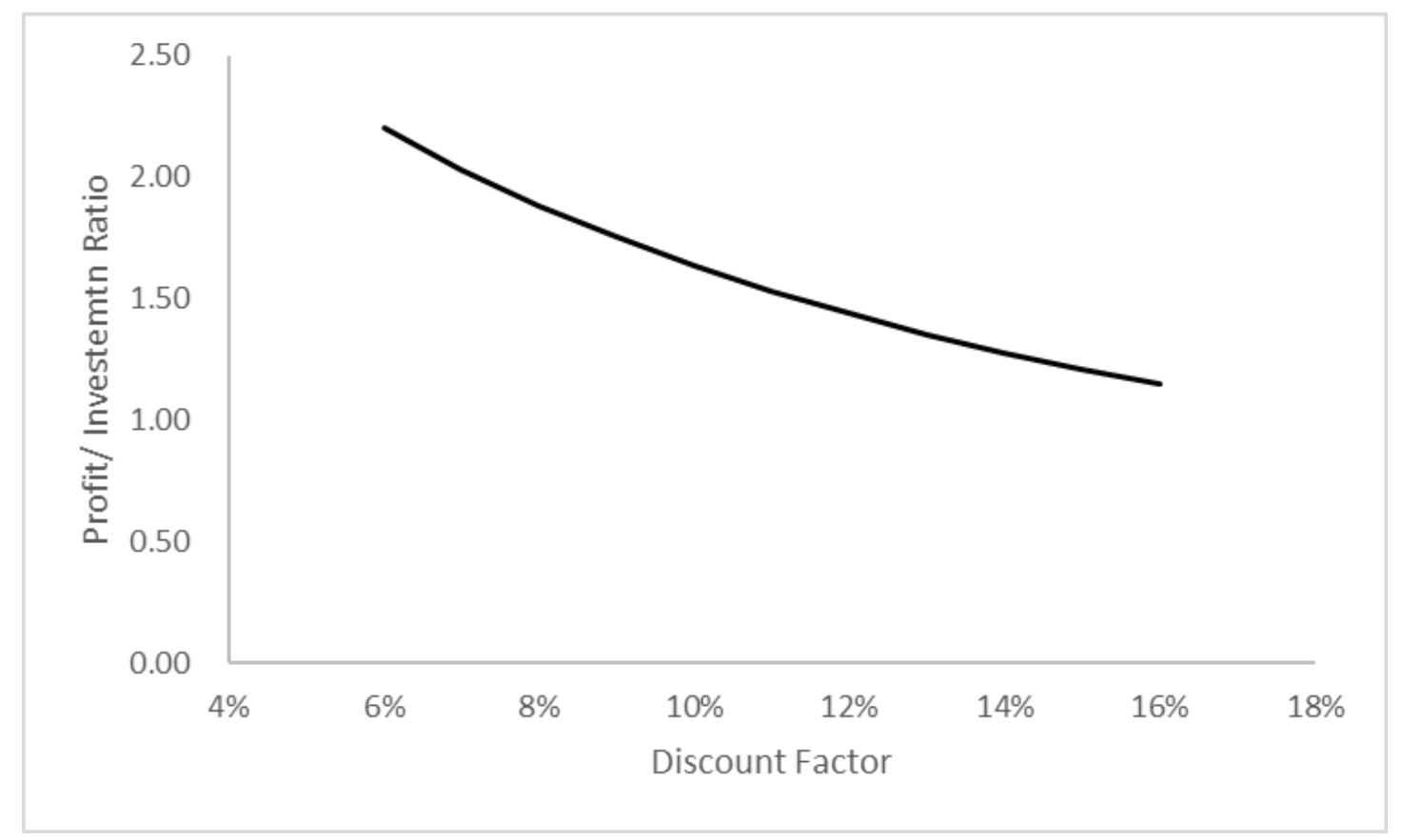

Figure 8. Discounted profitability index of the powerplant

The Profit/Investment Ratio is the ratio of discounted cost to initial investments as plotted in Figure 8 . The financial feasibility of the project at $10 \%$ discount rate, has a net present value (NPV) of $\$ 15,001,400.00$ (Php 761,167,600.00). Taking all periods equal, the discounted profitability index (PI) is $1.63(>1.0)$, return on investment (ROI) is $12 \%$, the internal rate of return (IRR) is 19\% (IRR>ROI), and a payback period of 5 years.

\section{Economic Feasibility}

Republic Act (RA) 9513 states that the power plant shall pay internal revenue tax after its seven year commercial operation. The Government will benefit from the Value-Added-Tax implementation on the seven year operation, plus the customs tax and duty tax, as well as the business related taxes.

The biodigester-pyrolyzer-Rankine generator will generate revenue as a pioneer enterprise for waste collection, segregation, treatment and disposal at the Environmental Sanitation Center of Muntinlupa City. Since the peak demand for electricity rises during the semester break during the summer season, revenues can also be generated by selling the electricity to the grid.

Savings can also be generated by lower expenditures for health and increase revenues for tourism by having a good solid waste management per area or barangay. The shift to a wasteto-energy could assist in the improvement of hygienic and environmental conditions of the city [8]. If $95 \%$ of generated waste convertible to energy are transformed, and the remaining 5\% or recyclables are sold as scrap, there is an increase in the acceptability of the city for tourism, and health hazards are lowered by the absence of waste accumulation. 


\section{Conclusions and Recommendations}

The residential residual waste disposal and electricity generation via biodigester-pyrolyzersteam Rankine cycle generator has been found feasible promising a return on investment of $12 \%$ and a payback period of 5 years. The internal rate of return was calculated to be $19 \%$. In addition, the City of Muntinlupa can properly dispose of 90 to $95 \%$ of its residual waste by converting it to electricity. It shall be able to empty most of its landfill in compliance will environmental and health laws. A detailed design of the equipment and plant and further simulation of the financial model is recommended. Further recommended that the business plan be formulated to assure sustainability of the plant.

\section{Acknowledgment}

The authors would like to express their appreciation to the City of Muntinlupa - Environmental Sanitation Center for providing necessary data and the Alejandro Melchor Professorial Chair in Engineering.

\section{References}

[1] World Energy Council, World Energy Resources 2016, World Energy Council, London, United Kingdom and Northern Ireland, 2016.

[2] A.L. Castillo and S. Otoma, "Status of solid waste management in the Philippines," In: The 24th Annual Conference of Japan Society of Material Cycles and Waste Management, Japan Society of Material Cycles and Waste Management, Asahikawa, Japan, p. 677, 2013.

[3] Y. Zhao, Municipal Solid Waste Management and Waste to Energy Possibilities in the Philippines, Unpublished MSc Thesis, Lappeenranta University of Technology, Lappeenranta, Finland, 2017.

[4] R. Soos, Financial Aspects of Solid Waste Management, Climate and Clean Air Coalition - Municipal Solid Waste Initiative, Dar es Salaam, Tanzania, 2017.

[5] Muntinlupa City Local Government Unit, About Muntinlupa, 2019 [Online]. Available: www.muntinlupacity.gov.ph/ [Accessed: July 2019].

[6] Muntinlupa City Environmental Sanitation Center, Waste Analysis and Characterization Study Report, Muntinlupa City, Philippines, 2018.

[7] A.H. Igoni, M.J. Ayotamuno, C.L. Eze, S.O.T. Ogaji, and S.D. Probert, "Designs of anaerobic digesters for producing biogas from municipal solid-waste," Applied Energy, Vol. 85, No. 2, pp. 430-438, 2008.

[8] Deutsche Gesellschaft für Internationale Zusammenarbeit (GIZ), Waste-to-Energy Options in Municipal Solid Waste Management: A Guide for Decision Makers in Developing and Emerging Countries, Bonn, Germany, 2017. 